\title{
ESTUDIOS
}

\section{Las Relaciones Literarias}

$\mathrm{H}_{\mathrm{L}}^{\mathrm{L} \text { desartollo de la literatura en las Américas alcanza ya considerables }}$ vez son más necesarias las bibliografías, índices y antologías de la materia; el incremento de esta índole de publicaciones es notorio en los últimos años. Lo mismo puede decirse de los estudios dedicados a esclatecer las relaciones literarias entre autores, obras, géneros, épocas, corrientes, movimientos y países del continente. Si bien es cierto que éstos en su mayoría se refieren a la producción de lengua española, tales coordenadas y paralelos ayudarán sin duda a trazar capítulos más firmes de nuestra historia y crítica literarias.

El estudio que relaciona dos o más de los sujetos mencionados presta por consiguiente altos servicios a la integración cultural americana, al modo que los desempeña la literatura comparada en Europa. Las relaciones literarias constituyen, pues, una disciplina rica en alcances mediatos $e$ inmediatos, que conviene fomentar generosamente. Incluso la idea de "relacionar" parece más cordialmente americana que la de "comparar", pues que ésta siempre entraña algún ánimo de presunción egoísta y no de comprensivo humanismo. A mayor abundamiento, esta actitud no puede ser resentida o separatista cuando trata de relacionar los esfuerzos y logros de América con la cultura europea; sino la de establecer por el acercamiento el justo deslinde entre nuestro débito con las culturas madres de Europa y los frutos conseguicios hasta ahora en América, para calcular con menos margen de error las aportaciones de la originalidad americana.

Son muchos ya los que se dedican a esta prometedora disciplina; sin tratar de agotar la bibliografía (la memoria suele también acarrear olvi- 
dos injustos), baste citar algunos autores que han llevado a forma de libro sus investigaciones: E. K. Mapes, sobre la influencia francesa en Rubén Darío; John E. Englekirk, sobre la de Edgar A. Poe en las literaturas hispánicas; Fernando Alegría, sobre 'Walt Whitman en la América Latina; Llorens Castillo sobre los liberales y románticos españoles e hispanoamericanos emigrados en Inglaterra; Alfredo A. Roggiano, sobre Pedro Henríquez Ureña en los Estados Unidos; Pedro Grases, sobre Andrés Bello en Londres; José de Onís, sobre los Estados Unidos como tema de los escritores hispanoamericanos, por sólo citar los más penetrantes o más voluminosos que se recuerdan de inmediato. Otro que yo me sé, ha trabajado sobre las relaciones entre Montalvo y Darío, de Menéndez y Pelayo y Montalvo, sobre Henry Fielding en el mundo hispánico, o sobre Unamuno y los mexicanos Reyes y Nervo, pero todavía no se juntan en volumen esas investigaciones.

En el caso de que los apuntes de hoy sobre temas análogos puedan considerarse demasiado teóricas o bibliográficos, quiero acompañarlos de una serie de ejemplos de relaciones literarias, unas ya estudiaclas, otras soslayadas, y una que otra desconocida aun de los especialistas, para mostrar prácticamente el provecho inmediato que puede sacarse de la atención presta'da a varios autores a la vez, aunque las conclusiones sean por ahora transitorias o interrogativas, como que se trata de un breve ensayo pretendidamente incitador y no del todo programático.

I) Martí-Sarmiento-Groussac. En las difusas aunque bien documentadas páginas de don Emeterio S. Santovenia ${ }^{1}$ y en una de Andrés Iduarte, lacónica pero incisiva, ${ }^{2}$ se habla de la carta que Sarmiento dirigió a Paul Groussac con motivo de la crónica de Martí sobre la inauguración de la estatua de la Libertad en New York, incitándolo a que la tradujera al francés "para que el teléfono de las letras la lleve a Europa, y haga conocer esta elocuencia sudamericana áspera, escapitosa, relampagueadora, que se cierne en las alturas sobre nuestras cabezas. Tradúzcala usted ... En español nada hay que se parezca a la salida de bramidos de Martí, y después de Víctor Hugo nada presenta la Francia de esta resonancia de metal". Iduarte transcribe el elogio textualmente y Santovenia lo diluye en su propia prosa, sin comillas; Iduarte señala bien claro al destinatario de la carta y su localización en las Obras de Sarmiento; Santovenia sólo dice que Sarmiento "quiso que se tradujese al francés el artículo

1 Genio y acción: Sarmiento y Martí. La Habana, Editorial Trópico, 1938, $270 \mathrm{pp}$. He consultado el texto en la recopilación de Estudios, biografías $y$ ensayos, del propio Santovenia (La Habana, 1957), pp. 581-613.

2 Martí escritor. México, Cuadernos Americanos, 1945, p. 264. En la segunda edición (La Habana, 1951), p. 223. 
de Marti', sin mencionar al posible traductor. La carta de Sarmiento a Groussac consta en la primera serie de Obras completas y en la de $19000^{3}$ pero no se ha examinado con detención.

En principio, hay que reconstruir la historia de esta carta. La de Martí al director de La Nación está fechada en New York, a 29 de octubre de 1886, y se publica en este diario bonarense el I die enero de I887 (al parecer, el correo tardaba poco más o menos dos meses; en este caso, los meses de noviembre y diciembre enteros). La carta de Sarmiento a Groussac se publicó también en La Nación, el 4 de enero de 1887, es decir que Sarmiento la redactó casi inmediatamente después de leer la de Martí, como se puede corroborar por el estilo die la propia carta, escrita bajo la fuerte impresión de la crónica de Martí. Esta carta de Sarmiento es bien "martiana", como se ve desde el comienzo, que termina con esta declaración impersonal, pero muy significativa: "Nosotros también hablamos ese lenguaje". Y el lenguaje es éste: "Ahora pídole su concurso para llevar a todas partes con el francés, que es la lengua universal del espíritu humano, la palabra americana, genuina, sintiendo a selva virgen, a cascada del Niágara, a cadena de los Andes, a corrientes de agua como el Misisipí o el Plata, a Pampa en fin, que deja ver la curvatura de la tierra, sin obstáculo humano que oponerle, aunque fuera el puente de Brooklyn, o alguna pirámide tlascalteca o de quien sea, que deja enanas las de Egipto. Bret Hart, desde California, ha maravilla'do a la Europa con aquellos ronquidos de oso gris, o malciciones de tahures que juegan millones en pepitas de oro".

A su vez, Santovenia ha novelado las impresiones de Martí al conocer la carta de Sarmiento a Groussac: "Martí se conmovió al leer la opinión que de él tenía Sarmiento. No existían relaciones personales entre ellos. El cubano había llegado a sospechar que el argentino no se inclinaba a ser su amigo, por la discrepancia de sus juicios sobre los Estados Unidos. Y Sarmiento lo sorprendía con un elogio tan extremadamente honroso que él deseaba exhibirlo, como regalo ce hijo a padre, en Cuba. Por una vez rompió Martí las normas de su modestia. Pensó, más que en sí mismo, en aquello para que podría servir en el futuro de su patria: lo alegraría ver republicado en La Habana aquel juicio de Sar. miento". De esta republicación, es lo cierto, no tenemos ninguna noticia; Peraza, puntal bibliógrafo de Martí, registra únicamente la de $E l$ Mundo, de La Habana, de 28 de enero de 1953, cuando el centenario de Martí.

Sin embargo, Santovenia tiene en parte razón. Martí debió sentirse

3 Vol. XLVI, pp. 175-176, y vol. XVI, pp. 166-167, respectivamente. 
satisfecho con la carta de Sarmiento. Podemos estar seguros de esto, porque el propio Martí la envió a México, al diario El Partido Liberal, en el que comenzó a colaborar a mediados de I886. La misma crónica sobre la estatua cie la Libertad, con idéntica fecha de redacción y texto, pero con más amplio sumario, apareció en El Partido Liberal el I8 de noviembre de 1886." Es la "Correspondencia Particular de José Marti" No. I9 en este diario. La carta de Sarmiento, con el título de "La Libertad iluminando al mundo" y con la aclaración de que se trata de un "Juicio del General Sarmiento sobre la última Correspondencia ce José Martí, publicada por La Nación del $I^{9}$ del corriente" se inserta en El Partido Liberal el $2 \mathrm{I}$ de mayo de $1887.5 \mathrm{La}$ diferencia de fechas entre las publicaciones de México y de Buenos Aires se debe, como es fácil advertirlo, a la distancia menor entre New York y México, en el caso de la crónica, y al recorrido mayor de Buenos Aires a New York y de New York a México, en el de la carta de Sarmiento.

Otras "simpatias" de Martí por Sarmiento se pueden seguir a través de sus colaboraciones en El Partido Liberal; tres de ellas, póstumas, lo que vale decir más desinteresadas porque ya no podían tener correspondencia de parte de Sarmiento. La colaboración No. IO2 en El Partido Liberal versa sobre La Pampa: moeurs sad-américaines, obra de Alfred Ëbelot con ilustraciones de Alfred Paris, recién publicada. ${ }^{6}$ Esta pieza de

4. Tomo III, No. 518, pp. 1-3. La numeración de las colaboraciones de Martí en El Partido Liberal es unestra, fruto de una investigación exhaustiva que habrá de publicar el Instituto Bibliográfico Mexicano, Biblioteca Nacional de México.

5 Tomo IV, No. 665, pp. 4 y 5. El origen de esta inserción está documentada en las Cartas a Manuel $A$. Mercado, epistolatio de Martí publicado en México, Universidad Nacional Autónoma de México, 1946, pp. 173-174. La carta, datada erróneamente en 1888, se puede fechar con exactitud el 19 de abril de 1887, día de su correspondencia sobre Whitman: "Aquí le mando mi carta a El Partido -escribe Martí a Mercado- en la que hallarán que leer los poetas, a quienes he tenido en todas las anteriores olvidados. $Y$ sí le ruego que suplique que en la imprenta que la corrijan con atención, y tan como va, con sus guiones y comillas; porque las de Beecher y Stewart me vinieron con errores y contrasentidos de importancia. Ya sé que mi mala letra tiene la culpa de esto; pero los caballeros cajistas entenderán que amo a los hombres, como Walt Whitman, y me lo perdonarán./En paquete separado le mando una carta que acaba de publicar a propósito de mí en Buenos Aires el glorioso y anciano ex Presidente Domingo Sarmiento. Ya verá qué enormidades dice; pero yo se la envío con placer, para que vea que su amigo no lo deshonra. Si U. cree que El Partido deba reproducirla, para que se vea que tiene en casa gente estimada, envíeme algo más de un ejemplar, porque a mi tierra no la he mandado, y así satisfaria el deseo pueril de que se leyese esa exageración en mi tierra. No me diga orgulloso. Pero endulza mis penas el sentirme amado./Y esa carta a que Sarmiento se refiere me ha traído muchas muestras de cariño de Buenos Aires, siendo las más curiosas las de los españoles, que hicieron fiesta nacional de mi éxito, y están empeñadísimos en que yo no sea cubano". Escary).

6 Paris, Maison Quantin-Buenos Aires, J. Escary, 1890. 312 pp. (Bibiothèque 
Martí ès conocida por su inserción en El Sudamericano, de Buenos Aires, 20 de mayo de I890; en El Partido Liberal aparece con cinco meses de anticipación, I9 de diciembre de $1889 .{ }^{7}$ Santovenia parece conocer este texto, porque en su monografía figuran algunas frases que lo tecuerdan o que no pudieron haberse escrito sin haberlo leído; de todas maneras, figura en las Obras de Martí, hasta en las desastrosas de la Editorial Lex. ${ }^{8}$ Lo que corresponde a Sarmiento es brevísimo: A la Pampa "Ia cantó el gran Sarmiento, en su Civilización y barbarie, libro fundador, donde se narran los combates de Aldao, el fraile terrible, y del tigre Facundo Quiroga". Nada más; pero es significativo que Martí haya penetrado tan certeramente en el símbolo "tigre Facundo" de Sarmiento, como se ve, cosa que no vio Santovenia, en el magistral ensayo sobre "Nuestra América".

Este ensayo, bien difundido ya y valorado, se publicó también originalmente en El Partido Liberal, 30 de enero de I89r." El pasaje pertinente es el que sigue: "Con los oprimidos había que hacer causa común, para afianzar el sistema opuesto a los intereses y hábitos del mando de los opresores. El tigre, espantado del fogonazo, vuelve de noche al lugar de la presa. Muere, echando llamas por los ojos y con las zarpas al aire. No se le oye venir, sino que viene con zarpas al aire. No se le oye venir, sino que viene con zarpas de terciopelo. Cuando la presa despierta, tiene al tigre encima. La colonia continuó viviendo en la república; y nuestra América se está salvando de sus grandes yerros - de la soberbia de las ciudades capitales, del triunfo ciego de los campesinos desdeñados, de la importación excesiva de las ideas y fórmulas ajenas, del desdén inicuo e impolítico de la raza aborígene-, por la virtud superior, abonada con sangre necesaria, de la república que lucha contra la colonia. El tigre es. pera, detrás de cada árbol acurrucado en cada esquina. Moritá, con las zarpas al aire, echando llamas por los ojos". ¿Quién negará que hay mucho Sarmiento en este pasaje? ¿No está aqui en síntesis todo el Facundo y hasta algunas imágenes del tigre cebado de la biografía del caudillo?

Otra referencia a Sarmiento y al Facundo se encuentra en una pieza desconocida hasta hoy. Se trata de una recensión de la obra de Frank W. Blackmar. Spanish Institutions of the Soutbwest, ${ }^{10}$ que envió Martí como colaboración No.r29 a El Partido Liberal, que la publicó el 25 de noviem-

7 Tomo VIII, No. 1434 , p. 1.

8 Vol. II, pp. 364-371.

9 Tomo XI, No. 1766, p. 1.

10 Frank Wilson Blackmar (1854-1931), Spanish Institutions of the Soutbwest. Baltimore, The John Hopkins Press, 1891, xxv, 353 pp. (Johns Hopkins University Studies in Historical and Political Science, vol. $\mathrm{X}$, extra). 
bre de r89r." "Apenas sabemos en nuestra América-dice Martí- los unos de los otros, pero todos vamos a una, como movidos por secreto resorte, estudiado, allegando, proponiendo lo mismo. Saberse de memoria a Taine no vale tanto, para gobernar el territorio de Tepic, como conocer hombre a hombre y costumbre a costumbre el territorio. Ni con galos ni con celtas tenemos que hacer en nuestra América, sino con criollos y con indios. Lo que Sarmiento, el primero, hizo en la Argentina con su libro fundador, su famoso Civilización y barbarie, lo hacia Justo Sierra hace un año en México. Es necesario conocernos para gobernarnos. Es necesario estudiar la potencia de nuestra virtud, para no fiar de ella, ni desconfiar más de lo justo; y las causas de nuestros defectos, para irlas aminorando gradualmente con la aminoración de las causas. Un defecto a veces ¿qué es más que la forma y tesón de una verdad?".

Quizá por el placer de transcribir textos de Martí, que todavía conservan actualidad, nos hemos apartaco del otro miembro de la ecuación que al principio expusimos: Paul Groussac. Nadie que sepamos se ha interesado hasta hoy en averiguar el resultado de la carta de Sarmiento al francés-argentino. No parece posible que Groussac haya desoído la petición de Sarmiento; sin embargo, de existir la traducción francesa de la crónica de Martí, no se ha localizado aún ni persona alguna se ha referido a ella. En I887, Sarmiento está en la cumbre indiscutida de su prestigio; sus palabras de consejo o de sugerencia tienen efectividad de órdenes, máxime en la persona de Groussac, a quien Sarmiento había asociado en otras ocasiones a sus tareas de difusión cultural. Sarmiento así lo declara al comienzo de la carta: "Otra vez nos hemos encontrado patrocinando los mismos propósitos de popularizar las ideas y los conocimientos en América, trayendo al castellano las que agitan la mente humana en otras lenguas. Ahora pídole su concurso para llevar a todas partes con el francés ... la palabra americana..." Más adelante insiste Sarmiento: "y aquí viene el objeto de esta carta, y es pedirle que traduzca al francés él artículo de Martí..." Al final, la petición es más vehemente: "Tradúzcala usted, que es nuestro bibliotecario inmérito, aunque sea nuestro lite-

11 Tomo XII, No. 2012, p. 1. Esta crítica de Martí sobre el libro de Blackmar no se encontraba ni en la más completa edición de Obras de la Editorial Trópico; empero hoy figura en la nueva edición de la Editorial Nacional (La Habana, 1963-1965), vol. 7, pp. 58 y ss., sin indicar el nombre de quien la proporcionó: cf. la "Guía", vol. 27, p. 83. En esta misma "Guía", preparada por Gonzalo de Quesada, Jr., al registrar el material de "Escenas norteamericanas", vol. 9-12, se dice lo siguiente: "Su reseña [de Martí] titulada 'Fiestas de la estatua de la Libertad', hizo tan honda impresión en Sarmiento, por el vigor de su lenguaje, que sugirió se tradujera al francés" (p. 98); pero no se plantea la interrogación de si se llevó a efecto o no la sugerencia de Sarmiento. 
rato francés, y se halla en buen camino de merecer su puesto. . . Tradúzcala, regáleme el manuscrito o dele publicidad de su cuenta; las letras americanas le deberán un servicio, y hará usted uno muy grande a este país, donde tiene posición y familia". Aunque algunas de estas últimas frases suenan poco delicadas en una carta pública, como el of recimiento de la dirección de la Biblioteca Nacional que no mucho después conseguiría Groussac, y el subrayar la situación personal que un extranjero había obtenido en la Argentina, no debieron ser obstáculos mayores para que Groussac se pusiera a la tarea encomendada; recuérdese el ascen'diente patriarcal que Sarmiento ejercía sobre la intelectualidad argentina, sobre todo en la redacción de La Nación, a la que Groussac pertenecía.

En cuanto a la simpatía que éste pudo tener por Martí, nada sabemos tampoco; no obstante podemos inferir que conocía bien sus escritos, especialmente sus crónicas de New York publicadas en La Nación, que los contaba a ambos como colaboradores de planta. No desconocería Groussac otras labores de Martí, por cierto análogas a las que Sarmiento lo asociaba, como la de traductor de obras científicas extranjeras. Martí tradujo las Antigüedades romanas, de A. S. Wilkins, y las Antigüedades griegas, de J. H. Mahaffy, en 1883, para la casa Appleton. Una carta de Groussac, fechada en Tucumán, I6 de mayo de I879, figura con carácter de prólogo aprobatorio en otro manual de la misma casa: Nociones de bistoria de Grecia, de C. A. Fyffe, en una edición de 1880.12 Podía, pues, Groussac, de no tener admiración explícita por Martí, considerarlo como colega en varias actividades. Nada por esta parte impedía la traducción, sino más bien la facilitaba. ¿Dónde se habría publicado esa versión francesa de la crónica de Martí? Importa averiguarlo, pues nos sitúa tempranamente a Martí en el ámbito de la cultura francesa.

2) iWhitman-Martí-Díaz Mirón. En El Partido Liberal publicó también Martí, como colaboración No. 33, su correspondencia sobre Walt Whitman, el 17 de mayo de $1887 .{ }^{13}$ Se conoce la fecha de redacción: New York, rg de abril del mismo año, y de publicación en La Nación de Buenos Aires, 26 de junio. Otra vez la menor distancia de New York a México da la prioridad a la inserción mexicana. El ensayo de Martí es

12 Cartillas bistóricas. Nociones de bistoria de Grecia, por C. A. Fyffe. Nueva York, D. Appleton y Compañía, 1, 3 y 5 Bond Street, 1880. xii, 177 pp. $\mathrm{L}_{a}$ carta-prólogo de Groussac está dirigida a Ángel Estrada, que era Agente General de los Appleton. A pesar de que las traducciones de Martí son de 1883, ya aparecen anunciadas en la última tapa de mi ejemplar de la Cartilla de Fyffe; no se trata de una premonición comercial, sino de una encuadernación a posteriari que se aprovechó para publicidad de los libros que "Acaban de publicarse", como reza el título del anuncio.

13 Tomo IV, No. 662, pp. 1 y 2. 
justamente célebre; permitió el conocimiento del poeta norteamericano en la América Latina y Darío lo declaró como una de las fuentes informativas de su soneto a Whitman en la segunda edición de $A z u l$ (i89o). No se conoce, en cambio, el comentario que Salvador Díaz Mirón le dedicó en su Diario Comercial, de Veracruz. El Partido Liberal lo reprocujo, con el título de "Las correspondencias de Martí" y con este único dato marginal como encabezado: "Habla en la gacetilla del Dicrio Come*cial Salvador Díaz Mirón", el 24 de mayo de I887.

El Partido Liberal, en su número correspondiente al $\mathrm{I} 7$ del actual mes [de mayo], trae una correspondencia fechada en Nueva York [I9 de abril de 1887] y firmada por José Martí, el insigne escritor cubano. Dicha correspondencia constituye un juicio hímnico y resplandeciente sobre la poesía de Whitman, de ese patriarca partentosamente lírico, de esa especie de profeta ardoroso y sobrehumano, que en versículos ígneos y radiosos propaga, como un incendio por un bosque, el amor a la naturaleza. Nunca hemos comprendido de tan clara manera, ni admirado por tan extraordinario modo el genic atlético, explosivo, delirante, prodigioso, del bardo mexicano, como cuando hemos leído la crítica magnífica de Martí, crítica que más parece un cántico libre del mismo Whitman. José Martí tiene razón: Whitman no es un loco del ritmo; es un colosal artista, a pesar de las incontenibles fugas ce su imaginación sin frenos, y no obstante de la temeraria excentricidad de su numen apocalíptico; o acaso precisamente por esa excentricidad y por aquellas fugas. La poesía de 'Whitman no es una demencia amatoria y sinfónica; es la suprema razón desleída en maravillosas ternuras, en una fantasía ilimitada e impetuosa; es la luz del sol espléndidamente cescompuesta en arcos de las cataratas del Niágara. Las obras de Whitman no son de aquellas que trasponen fácilmente el dintel del hogar. Hay en ellas demasiado calor, demasiada animalidad, demasiada madurez para que la virgen y el doncel puedan leerlas sin peligrosos estremecimientos... Whitman ama filialmente a la naturaleza, pero a su modo; ni muestra la irreverencia ce Cam ante las impudicias de Noé, ebrio y dormido a la sombra del arca detenida en la montaña de Armenia, ni se sirve del manto que Sem y Jafeto arrojaron sobre ellas.

Pero nos hemos alejado mucho de nuestro objeto. Nuestro objeto era simplemente felicitar al Partido Liberal porque cuenta con un colaborador de la talla de Martí y recomendar a nuestros 
suscriptores la lectura de la correspondencia de éste. Lo demás huelga. ${ }^{14}$

Esta breve pieza desconocida de Díaz Mirón nos pone sobre nuevas pistas de exploración que hasta ahora no se tenían. ¿Algo de Whitman a de Martí pasaría a la poesía o a la prosa del veracruzano? Por lo menos en ésta, el tema de la correspondencia cie Martí acarreó algo más que palabras e imágenes. Conviene, pues, echar de nuevo las redes en la obra de Díaz Mirón.

Aunque peque de excesivo en la transcripción de textos ajenos, quiero de una vez copiar un fragmento de otra correspondencia de Martí, que pudo conocer Díaz Mirón y también Rubén Darío, por haberse publicado en El Partido Liberal, pero desconocida para los devotos martianos y por lo tanto aurente aún en las Obras completas de Martí, hasta en las más completas impresas en La Habana recientemente (1963-1965). Fue la colaboración No I 34 de Martí en ese diario, fechada en New York el 25 de marzo de 1892 , el mismo día de la muerte de Whitman. Apareció en México el 8 de abril de 1892, como penúltima colaboración. ${ }^{15}$ Sólo se copia el principio y el final referente a Whitman.

Estos han sido días de caer. En su tumba heroica, hecha como de dólmenes, está ya el cuerpo del poeta 'Walt 'Whitman... Allá, como una luz, en la casita blanca de Camden, se fue la vida dolo. rosa de aquel cuerpo que pareció a Lincoln el de mejor equipo de toda la casta americana. Walt "Whitman iba entonces, después de la guerra doncie estuvo de enfermero a llevar a los "camaradas" de los hospitales el placer que les podía comprar con los ahorros de su cuarto de soltero: iba robusto, de fieltro militar, con el bigote y la perilla del Sur, y el cuello entero al aire. Ahora vivía en la silla de la enfermedad, del consuelo de las cartas de Inglaterra, que lo proclama poeta grandioso, y de la cariciad de sus amigos: en las manos tenía el báculo siempre: la melena de los setenta y tres años, marco imponente de la cara leonina, le caía rizada por los hombros: alli estaba, viendo venir "el cercano, curioso, sombrío, incierto espectro: ¿y volveré a quedarme en esta vida, viejo, lento, cotorrón, con la voz cascada que chilla y parlea, o se abrirán los cielos y los soles?" Allí estaba, poniendo en su ritmo extraño, entre hebraico y aborigene, su pensamiento desnudo y como descoyuntado, sin 
miedo a palabra ce hombre ni a visión femenina: tal un águila, en un cuarto de mujer, ahora clava y desgarra un pañuelo de seda, ahora rompe de un picotazo el vaso de cristal y sube al aire la potente esencia, ahora alza la cortina, y le ve a la hermosa el sueño.

De padre de Inglaterra y madre de Holanda nació el niño que besó a Lafayette; que vio campo y trabajo desde que abrió los ojos grises: que entró en el pensamiento por el plomo de las cajas de imprimir, que fortaleció la adolescencia con su empleo de maestro ambulante de casa campesina, que en las ciudades prefería a la amistad de los magnates la de los guías de los ómnibus, que al caérsele de cnfermedad las riendas a un cochero amigo se las alzó por todo Broadway para ganarle el jornal a la familia, que de la dignidad de cabecera de un gran diario bajó a ganapán por la culpa de poner en verso rugoso su admiración libre del génesis, perenne y amor vivido de la naturaleza; que en la guerra escogió el oficio de dar ternura y medicina a los heridos; que del puesto rehecho de periodista mayor salió para acompañar al hermano pobre y moribundo por las montañas y los prados donde el aire fragante renueva la vida; que al volver de la peregrinación de los lagos y árboles gigantescos, se anunció de maestro de obras y cepilló madera con sus manos; que el oficio mezquino de la gobernación, de que lo echó una vez por la culpa de su poesía un secretario paviculto, salió a la limosna de su casa de familia, donde le llevó el pan de enfermo la admiración inglesa; que en los últimos días de sol de su vida natural iba hilando los metros abruptos donde hierven desnudos el hombre y la mujer, a ver cómo encajaban las piedras colosales de las sepulturas de puertas de granito donde dice, con letras acuchilladas: "Walt "Whitman".

3) Martí-Whitman-Dario. Este caso ha sido tratado con amplitud e insistencia por don Manuel Pedro González, en dos famosas ponencias presentadas al Congreso de Escritores Martianos que se reunió en La Habana con motivo del centenario de Martí, en 1953. Se han impreso en la Memoria correspondiente (La Habana, I953) y en las Indagaciones martianas del autor (La Habana, 1961). Don Manuel Pedro González ha rastreado con cuidado los débitos martianos de Darío (cosa que Darío nunca ocultó), siguiendo "La huella de Martí en Rubén Dario", de Osvaldo Bazil, conferencia de I932, donde se adelanta la exagerada tesis de que "sin Martí, no hay Rubén", si bien èl nuevo expositor insiste en no abrigar "la más leve intención de deprimir a Rubén Darío". "16 Como

16 "Iniciación de Rubén Darío en el culto a Marti" y "Resonancias de la 
esas Indagaciones martianas se me reprocha no haber esclarecido la influencia de Martí en Dario, en una época de éste en que aquélla no existía, y aun se me prescribe "una mayor familiaridad con la obra de Martí", quiero ofrecer en descargo algunas pistas insospechadas que pueden conducir a una mejor comprensión del caso Martí-Darío; aunque por hoy sólo se refieran a su intersección con Whitman, ellas nos llevan a inferir otras relaciones que, además de las literarias y personales que unieron a Martí y Darío, los vuelve colaboradores en la empresa de dar a conocer los valores americanos en Europa. ${ }^{17}$

Dejaremos de lado las imprecisas lecturas que Darío pudo hacer de Martí en Nicaragua, antes del viaje a Chile (junio de I886); aunque es cierto que el Dario chileno pretende remontar su conocimiento de Martí a la época guatemalteca de éste, cuando escribe en I 888 que "Martí alcanzó a escribir en El Porvenir de Guatemala algunos artículos, y después partió", años $1877-1878$, no es posible creer que un niño entre los diez y los once años, esos tenía Darío en tales fechas, pudiera retener para uso muy posterior las complejas peculiaridades de la prosa martiana. Máxime si comprobamos que Martí debió de escribir muy poco para $E l$ Porvenir; David Vela, que ha investigado el periódico, menciona gacetillas sobre Martí, pero sólo una pieza propiamente suya, una carta a Salvador Falla, 'de febrero de 1878 , réplica al artículo "La poesía", de Falla, publicado el 25 de enero del mismo año. ${ }^{18}$ Por otra parte, en la prensa de Nicaragua no se registran reproducciones periodísticas de Martí antes del viaje de Darío a Chile; la primera parece encontrarse en El Diratio Nicatagüense, de Granada, 8 de marzo de $\mathrm{x} 887$, sobre la "Revolución en la enseñanza".."

Todo, pues, obliga a pensar que Darío "descubrió" literariamente a Martí, ya en Chile, a través de las correspondencias publicadas en La Nación de Buenos Aires. Y quizá sólo a partir de la crónica sobre Whitman, de 1887 , pues las similitudes que don Manuel Pedro González encuentra en la prosa periodística de Darío, anteriores a esta fecha, no

prosa martiana en la de Darío (1886-1900)". La separata de la Memoria tiene $67 \mathrm{pp}$. En las Indagaciones martianas ocupan las pp. 197-273. Una adición ocurre en la p. 209, entre un paréntesis: "Cuando escribí este trabajo no conocía un apunte que Martí dejó inédito en el que indicaba su propósito de escribir un artículo sobre Dario. Nunca lo publicó. 1961". Véase ahora ese apunte en el vol. 18 de la nueva serie de Obras completas, (La Habana, Editorial Nacional, 1963. 1965) p. 287.

17 Don Manuel Pedro González, que maneja en estos trabajos la edición de 1952 de las Poesías completas de Darío, hecha por don Alfonso Méndez Plancarte, no ha reparado que en la nota correspondiente al soneto a Walt Whitman, p. 1321, se lee, desarrollando las abreviaturas: "El artículo de Martí, en $L a N a-$ ción de Buenos Aires, 26 de junio de 1887: comunicación de Mejía Sánchez". 18 Año III, serie 33, No. 799, p. 2. 
parecen del todo convincentes. En cambio, el deslumbramiento de Darío ante la prosa de Martí de I887 es seguramente demostrable, ya que cuaja en el III de los "Medallones" del Azul de 1890 . El propio Darío, en la nota XXXI de esta edición, declara a manera de fuente de su soneto a Whitman, aquella crónica martiana que considera como "una de sus más bellas producciones en La Nación de Buenos Aires". En Los raros de 1896, necrologia de Martí del año anterior, recuerda, entre otras crónicas mattianas de fecha posterior, la dedicada "al bíblico autor de las Hojas de hierba" como caracterización del personaje: "un "Whitman patriarcal, prestigioso, líricamente augusto", la misma imagen que Darío había trasladado al soneto. Puo, pues, en muy buena pista don Manuel Pedro González a don Andrés Rodríguez Ramón al sugerirle "el cstudio comparativo del léxico" de ambas piezas. Aunque el trabajo del profesor Rodríguez permanece inćdito (por lo menos hasta el año I96I), ya en x953. pudo adelantar esta conclusión a su colega californiano: "De la comparación que antecede resulta que de las 57 palabras que he copiado del soneto de Dario, hay 35 que aparecen exactamente en el artículo de Martí, además de 8 palabras que sin ser idénticas a las de Martí son casi iguales, haciendo un total de 43 palabras. $Y$ si agregamos la palabra 'boga' que utiliza Darío, de idéntica acción a la palabra 'rema' que aparece en Mattí, pudiéramos fijar el total en 44 palabras. Esto quiere decir que unas tres cuartas partes del vocabulario del soneto de Darío aparecen en Martí".19

La conclusión, "reveladora" cegún don Manuel Pedro González, en realidad no lo es tanto. La coincidencia del mero léxico no es prueba definitiva; aun los polemistas que se encuentran sobre un tema pueden usar y de hecho usan un mismo vocabulario y sus posiciones son antagónicas. Es más revelador el examen estilístico que lleva a la comprobación de la "visión" del tema; pero en este caso ésta es tan evidente que se hace innecesario aquel examen. Sin embargo, no conviene exagerar. El saldo favorable a Martí en la génesis del soneto dariano puede rebajarse sensiblemente si agotamos las otras "fuentes" que Darío declaró. No las conocemos aún; pero pueden investigarse. Ahora sólo me interesa señalar el camino y destacar un aspecto muy positivo de Martí dentro de la historia literaria, que Dario dejó apuntado y que los martianos no han considerado, a mi modo de ver más importante que el léxico de un soneto, débito del que tanto se ufanan.

En primer término, convendtía fijar exactamente la factura del "medallón" whitmiano; pero esto todavía no ha sido posible. Lo dicho por Soto Hall y Edelberto Torres, sobre la lectura de Whitman por Darío

19 Indagaciones martianas, ․ 256. 
en Guatemala ( 1890 ), no impide la posibilidad de que el sonsto a Whitman se hubiera escrito en El Salvador ( $1889-1890$ ), como otros de la serie de los "Medallones",20 y que Darío sumara entonces a la lectura de Martí, la de las traducciones de Whitman que publicaba en I889 Francico Gavidia en el Reprortorio Salvadoreño.21 También vale señalar que en esta época, la inmediatamente anterior y posterior a la publicación del soneto en Azul (1890), Darío sigue de cerca las publicaciones periodísticas de Martí en un ejemplar del $N^{\circ}$ I de La Edad de Oro, junio de 1889 , escribió Darío su cuarteta "Chiripa", fechada en este año; ${ }^{-22}$ en El Correo de la Tarde, diario guatemalteco de Darío, se

20 Por lo menos el medallón de "José Joaquín Palma", el IV de los publicados en el Azul de 1890, se había publicado como I en el Repertorio Salvadareño, San Salvador, junio de 1889 , tomo II, No. 6, pp. 419-420, según se deduce de las investigaciones del doctor Diego Manuel Sequeira; cf. su Rubén Daría criollo en El Salvador, Managua, Editorial Hospicio, 1964, pp. 23-24. El colofón de la edición guatemalteca de $A z u l$ dice que se terminó de imprimir el 4 de actubre de 1890, pero el Diario de Centro América, de 16 de agosto del mismo año, la da ya como "lista y se pondrá en venta en estos días"; cf. Sequeira, abra citoda, p. 238, nota 2 .

21 Don Julio Saavedra Molina, que también localizó el medallón de "José Joaquín Palma" en el Repertorio Salvadoreño, agrega al respecto: "El soneto III ["Walth "Whitman"] puede tener relación con las traducciones de "Whitman que F[rancisco] Gavidia publicaba en 1889 en el Repertorio" (cf. Obras escogidas de Rubén Dario publidadas en Cbile. Tomo I. Edición crítica y notas de Julio Saavedra Molina y Erwin K. Mapes. Santiago de Chile, Universidad de Chile, 1939 , p. 367 , nota al verso 12 . Es corroborante el siguiente texto de Gavidia, que consta en un estudio suyo sobre Darío, publicado en el mismo Repertorio: "A Rubén no le agrada Cimbelina de Shakespeare por la figura de Imógena. En cambio va penetrándose de un gran panteísmo, y ama y sigue a Walt Whitman" (cf. su "Rubén Darío" en el Repertorio Salvadoreño, julio de 1889, tomo III, Na. 1, pp. 1-11, y ahora en Sequeira, obra citada, p. 34). Fernando Alegria en su Walt Whitman en Hispanoamérica. México, Studium, 1954, p. 253, ya toma en cuenta las traducciones whitmianas de Gavidia, aunque no las declara bibliográfica ni textualmente, y lo hacen pensar que "pudiera ser que Dario escribiera su poema a "Whitmah en 1889 durante su permanencia en El Salvador".

22 Fuera de las referencias encomiásticas de Martí en la prensa chilena, que ya han sido aprovechadas por don Manuel Pedro González, apunto la escritura de esta brevísima pieza en el No. de junio de 1889 de La Edad de Oro, de Martí, lo que señala a Darío como poseedor y lector de la revista; pero esto hay que demostrarlo previamente. La poesía en cuestión, según Saavedra Molina (Paesias y prosas raras, de Rubén Dario, Santiago, Prensas de la Universidad de Chile, 1938, pp. 15-16) y Méndez Plancarte, edición citadk, pp. 1025 y 1360, que lo sigue y cita, se "halló escrita de puño y letra del poeta en una de las últimas páginas de un ejemplar del libro Tres béroes de Juan Montalvo"; ahora bien, ningún impreso de Montalvo se titula así, sino el primer artículo del No. 1 de La Ediad de Oro, lo que se confirma con la fecha que se atribuye a dicha poesía: "Metapa, 1889", y con el tema de la misma: sin duda el fracasada matrimenio con Rosario Murillo en ese año, que lo hizo marcharse a El Salvador. Lo de "Metapa" debe ser invención del comunicante a mala lectura del ms., pues no se sabe de ningún viaje de Dario a Metapa, su pueblo nativo, durante su breve estadía nicaragüense en este año, entre marzo y abril. que transcurrió en las ciudades de León y Managua; por lo tanto "Chiripa" sólo pudo ser escrita en El Salvador y después de junio de 1889, fecha de la revista martiana. Esto tiene corroboración en un pasaje de Darío sobre "La vida en San Salvador.- 
publicaron dos crónicas estadounidenses de Martí, I9 de diciembre de I890 y 22 de enero de I89I. ${ }^{23}$ Pero en agosto de I889, cuando Darío escribe el Cap. VII sobre los "amigos" de $A$. de Gilbert, intercala una frase de Whitman que no figura en la crónica de Martí: "Contábame [un militar, pacificador de los indios araucanos] de cómo los caciques están tendidos en sus rucas, como señores perezosos...; cómo no se quitan el sombreno delante de mada ni die nadie, como dice el profeta yanké Walt Whitman que hace él; cómo tratan de tú al Presidente..."24 Lo cierto es que aquí hay una superposición de conocimientos; la frase: "el profeta yankee "Walt "Whitman" es de genealogía martiana. Pero la paráfrasis de Whitman y sobre todo el comentario de Darío: "como dice... que hace él", indican ya otros conocimientos, incluso textuales que pudo tener a través de Gavidia. ${ }^{25}$

Ahora recuérdese la nota de Darío a su "medallón" de Whitman en el Azul de ı890: "Walt Whitman. En mi opinión el más grande de los

Colegio de Santa Teresa", donde se lee: "que [a los niños] se les haga leer periódicos como el que publica José Martí, 'el hombre de La Edad de Oro', periódicos para ellos, que tienen historias que hacen llorar y cuentos que hacen reír, y que son escuela que instruye y guignol que arranca las grandes carcajadas" (cf. Sequeira, obra citada, p. 276; el texto procede La Unión, San Salvador, 12 de noviembre de 1889). Otro pasaje del Darío de esta época, aunque apoyado en un "se" impersonal, of rece un juicio no muy favorable al Martí traductor de Hugh Conway; al hablar de las "lindas novelas" que Eduardo Poirier traducía para los folletines de El Mercurio de Valparaíso, menciona su traducción de Recobrada [Called Back], traducida también por Martí con el título de Misterio y publicada por Appleton en 1886, y agrega: "Hay una edición especial de Recobrada, cuya traducción se considera superior a la de José Martí" (cf. Sequeira, obra citada, p. 86; el texto es de El Imparcial, Guatemala, 26 de septiembre de 1889, pero fechado en la hacienda La Fortuna, Sonsonate, El Salvador, 26 de agosto del mismo año).

23 José Martí, "Exterior. Estados Unidos", fechada en Nueva York, 9 de septiembre de 1890 y publicada en El Correo, 19 de diciembre del mismo año, año I, No. 11, pp. 1-2; y "En los Estados Unidos. Carta de verano-En las montañas", Nueva York, 1890, publicada en El Correo el 22 de enero de 1891, año I. No. 36 , p. 1. Ambas piezas martianas son conocidas; fueron publicadas también en El Partido Liberal de México y en nuestra investigación llevan los Nos. 115 y 119 , respectivamente.

24 A. de Gilbert. San Salvador, Imprenta Nacional, 1889 (en la portada exterior, 1890), pp. 70-71. Agradezco aquí este raro ejemplar a doña Emilia Ramero de Valle, viuda de mi maestro el Dr. Rafael Heliodoro Valle, q.d.D.g.

25 Alegría, obra citada, p. 253, acude a este pasaje, que Manuel Pedro González pasó por alto, y señala su procedencia: "I wear my hat as I please, indoors or out" (Song of Myself, 20). Igualmente cabe decirse de otro pasaje de Darío referente a Whitman, escrito en El Salvador, en 1889: "el profeta yankee Walt "Whitman, calca en inglés el versículo hebreo", que sí puede tener origen martiano ("Walt Whitman habla en versiculos, sin música aparente... parece un canto de patriarcas... habla 'en alaridos proféticos'... Un verso tiene cinco sílabas; el que le sigue cuarenta, y diez el que le sigue"); figura en el Prólogo de Asonantes (libro de Narciso Tondreau) publicado originalmente en el Repertorio Salvadoreño, julio de 1889 , tomo III, $N^{\circ} 1$, pp. $15-27$ (cf. Sequęira, obra citada, 46 y 49). En Alegría, abra citada, pp, 253-254. 
poetas de la América del Norte. En Francia no se le conoce aún lo suficiente. Un magistral estudio sobre la vida y obras de Whitman publicó en la Revue de Deux Montes Gabriel Sarrazin. Asimismo, José Martí le dedicó una de sus más bellas producciones en La Nación de Buenos Aires, y R[omán] Mayorga R[ivas] un excelente artículo en la Revista Ilustrada de Nueva York". ${ }^{26}$ El texto se ha usado para exaltar el influjo 'de Martí sobre Darío, únicamente; no para buscar y sopesar las otras fuentes. Comencemos por el orden en la declaración, que parece bien calculado, de más a menos. El primer turno corresponde a Sarrazin, pero no sólo en la mención sino en el apelativo y calificativo de su trabajo: "magistral estudio"; el segúndo a Martí, con "una de sus más bellas producciones"; el tercero, a Mayorga Rivas, por su "excelente artículo". Descontemos por ahora al último, el primero en la amistad personal de Dario, por no haberse localizado aún ejemplares de esa Revista Ilustrada de Nueva York, aunque está bien documentada su existencia. ${ }^{27}$

Nos queda en primer término Sarrazin, cuyo "magistral estudio" tampoco hemos podido localizar en la bien existente Revue de Deux Mondes (por lapsus de Dario), pero su texto puede ser consultado por quien tenga acceso al volumen de Sarrazin, La Renaissance de la poésie anglaise, 1798-1889. Deuxième série: Shelley, Wordsworth, R. Browning, Walt Whitman. Paris, Libraire Académique Didier-Perrin, I889, y quiera establecer con mayor justicia las fuentes del soneto de Dario. ${ }^{28}$ Nuestro

26 Azul... Segunda edición aumentada. Guatemala, Imprenta de "La Unión", 1890 , nota XXXI correspondiente a la p. 187, pp. 224-225. Id"em, en Indagaciones martianas, p. 234; ibidem, Alegría, obra citadia, p. 251.

27 Cf. Justo A. Facio, "La Revista Ilustrada de Nueva York", en Revista de Costa Rica, San José, enero de 1892, año I, No 3, pp. 142-151. Véase también la nota 1 al "Luis G. Utbina" de Manuel Gutiérrez Nájera en mi edición de las Obras de Gutiérrez Nájera: Crítica literaria, I. México, Universidad Nacional' Autónoma de México, 1959, p. 431. Alegría, obra citada, parece haber consultado el número de mayo de 1892 de esta Revista Ilustrada de Nueva York, pues en su bibliografía registra una "Necrología" de Whitman (XI, 255), p. 415, pero no se refiere al artículo de Mayorga Rivas.

28 En realidad, el estudio de Sarrazin, "Poètes modernes de l'Amérique: Walt Whitman", se publicó en la Nouvelle Revue, de París, 19 de mayo de 1888 (cf. Le Livre, París, 10 de junio de 1888, año IX, No 102, p. 333). Gay Wilson Allen, Walt Whitman Handbook (Chicago, Packard and Co., 1946), aunque anota la revista, no da el título del estudio, y lo fecha una vez en 1888 y otra en 1889; empero cita y trascribe trozos de la traducción inglesa, hecha por Harrison S. Morris, que figura en In re Walt Whitman. Philadelphia, David McKay, 1893. pp. 159-194. Alegria, que ha manejado el Handbook de Allen, identifica la revista, p. 251, peto no parece haber tenido el estudio a la vista. Ptesume que Dario debió leerlo en Chile, en casa de Balmaceda Toro ("A. de Gilbert"), pues ahí se amontonaban "sobre una mesa [los] diarios [y] las pilas azules y rojizas de la Nouvelle Rovue y la Revue de Deux Mondes" (son palabras de Datio en $A$. de Gilbert, edición citada, p. 30). La confusión en el cuarto de Balmaceda sugiere el origen de la inexactitud de Darío. También cita Alegría, p. 252, un párrafo de! artículo "A própósito de" un nuevo libro" (La Epoca, Santiago de Chile, 
propósito, ya lo hemos dicho, es otro: con sólo cotejar la fecha del volumen impreso de Sarrazin, donde figura el estudio sobre Whitman, y la de la crónica whitmiana de Martí (I7 de mayo de 1887 , en El Pavtido Libeval, y 26 de junio, en La Nación) se advierte la prioridad de ésta en la divulgación de la figura y obra de Whitman. Recuérdese que Dario anticipa en la nota citada que "en Francia no se le conoce aún lo suficiente", a pesar de que a continuación se refiere con elogio al estudio de Sarrazin. ¿No está queriendo decir Darío que en América él, Martí y Mayorga Rivas si conocen a Whitman? ¿O que con su soneto al que en su "opinión [es] el más grande de los poetas de la América del Norte" se está adelantando a la Francia de sus amores? ¿O sólo quiso señalar la injusticia de que en Francia no se conocía a Whitman suficientemente? Algo hay de todo esto. Y Darío tenía razón, como en seguida veremos.

Cuando en Le Livre, revista de "bibliographie moderne" de París, Io de julio de $\mathbf{r} 889$, se comenta el libro de Sarrazin, no se dedica una sílaba al último estudio, el más reciente sin duda. En toda la reseña, elogiosa en general con algunos reparos, no se menciona el nombre de Whitman, que figura en la portada del libro. Hasta se reclaman ausencias, como la de Byron, entre poetas que Sarrazin no quiso tratar por bien conocidos, y se le aconseja la inclusión, en futuras ediciones, de los nombres de ciertas miss Robinson y miss Blind, porque el resencionista, E. C[aro], nada menos, es buen conocedor de la literatura de lengua inglesa del pasado y del presente, pero ignorante de Whitman. ${ }^{29}$ En el número sigu:ente de Le Livre, ro de agosto de 1889 , encontramos unas frases referentes al conocimiento de Whitman en Francia muy semejantes a las de Dario; figuran en la "Chronique bibliographique", firmada con iniciales B.-H G[ausseron], que incluye un comentario sobre Indoor Studies (Boston and New York, Houghton, Mifflin and Co., I889), de John Burroughs (I837-I92I), amigo y discípulo de Whitman y quien primero escribió un libro sobre él. Del último ensayo de Indoor Studies, titulado "An Egotistical Chapter", dice Gausseron: "Nous demandons à en citer ces lignes, parce qu'elles contribueront à faire connaître la valeur d'un poète

16 de noviembre de 188̧8), testimonio de la "admiración [de Dario] que no parece basarse en un conocimiento directo de Leaves of Grass", ciertamente; pero que tampoco procede, ni por el estilo ni por las ideas, de la carta de Martí sobre Whitman, y sí puede provenit de Sarrazin. Alegría toma partido por los dos, de esta manera: "muy bien podría ser el eco de la emoción que le produjeron los inspirados conceptos del crítico francés y del cubano" (p. 251, in fine).

29 Año $\mathrm{X}$, No 115 , pp. 345-346. Las iniciales E. C. corresponden al colaborador E[Ime-Marie] C[aro], de la Academia Francesa. 
dont le nom a retenti partout, mais dont l'oeuvre est restée à peu près inconnue en France", 30

Es hora de citar el pasaje conocido de Los raros (1896) sobre las crónicas de Martí que Rubén Darío recordaba, entre ellas aquella de "un Walt Whitman patriarcal, prestigioso, líricamente augusto, [escrita] antes, mucho antes de que Francia conociera por Sarrazin al bíblico autor de las Hojus a a bierba'. ¿No está otra vez Darío invocando como orgullo propio el hecho de que Martí se adelantó, por lo menos en un año, al conocimiento y divulgación de Whitman? ¿Por qué se ha callado - o ignorado- este reconocimiento tan honroso en favor de Martí? No parece cosa de martianos. ${ }^{31}$

Otro pasaje de La vida de Rubén Dario escrita por él mismo parece coincidir en señalar el desconocimiento francés de Whitman. Aunqua Darío no alude en él a Martí, todavía está flotando en el ambiente su "voz dulce y dominadora al mismo tiempo", pues la escena que luego copiaremoz en palabras de Darío se sitúa cronológicamente en I893, en París, muy poco después de la entrevista que Darío y Martí tuvieron en Nueva York el 24 de mayo de ese año. El modo como Darío escribió su autobiografía nos ha privado sin duda de muchos detalles significativos; es válido suponerlos, aun a riesgo de caer en lo novelesco, porque de otro modo no se explican varias coincidencias de acción, tiempo y lugar. Con todo, la entrevista con Martí no está contada a la ligera; en cierto momento, y a los veinte años de distancia, pareciera que Darío, de pronto va a recordar los temas de su conversación con Martí, pues que ha conservado fielmente el calor de intimidad en que se desarrolló. "Allí -escribe en Igr2- escuché por largo tiempo su conversación. Nunca he encontrado, ni en Castelar mismo, un conversador tan admirable. Era armonioso y familiar, dotado de una prodigiosa memoria, y ágil y pronto para la cita, para la reminiscencia, para el dato, para la imagen. Pasé con él momentos inolvidables, luego me despedi... No le volví a ver más... Al día siguiente tomamos el tren Gonzalo [de Quesada] y yo, pues mi deseo era conocer la catarata de Niágara antes de partir para París y Buenos Aires". ${ }^{32}$ En esos momentos inolvidables ¿no hablarían de Whitman? ¿No le habría recomendado Martí alguna edición de Whitman? ¿No le habría dado Darío un ejemplar del último Azul?

Todo esto parece vislumbrarse en la autobiografía de Darío, casi

30 A $\tilde{\circ} \mathrm{X}$, № 116 , pp. 409-410. Las iniriales corresponden al colaborador B.-H. Gausseron, que en ese mismo número publica un estudio sobre Víctor Hugo.

31 Alegría, obra citada, p. 252, trae a cclación la cita de Los raros y sí se da cuenta de que Darío "destaca la prioridad del cubano"; pero él no la destaca.

32 La vida do Rubèn Dario escritat por él mismo. Barcelona, Casa Editorial Maucci, s. f., pero de 1915, cap. XXXI, p. 145. 
inmediatamente, al narrar una mañana de junio o julio de I893, cuando su primer estadía en París: "Una mañana, después de pasar la noche en vela, llevó Alejandro Sawa a mi hotel a Charles Morice, que era entonces el crítico de los simbolistas. Hacía poco que había publicado su famoso libro La littérature de tout à l'beure. Encontró sobre mi mesa unos cuantos libros, entre ellos un Walt Whitman, que no conocía. Se puso a hojear una edición guatemalteca de mi $A z u l$... Charles Morice fue bondadoso y tuvimos, durante mi permanencia en París, buena amistad, que por cierto no hemos renovado en días anteriores".33 Quiso decir "posteriores", seguramente; pero lo que importa señalar aquí son los libros: el Whitman, que Morice no conocía y el Azul del soneto a Whitman en manos de Morice. Alguno o los dos debió llevarse consigo, pues se conoce un Paul Verlaine (Paris, Léon Vanier, I888), de Morice, con dedicatoria "A Monsieur Rubén Darío, bien cordialement", como prenda de un posible canje de libros. ${ }^{34}$

En 1893 seguía siendo Whitman un desconocido para el crítico de los simbolistas. $Y$ tocaba a dos hispanoamericanos el contribuir a la difusión de Whitman en la literatura francesa, por lo menos a picar la curiosidad de uno de los consagrados del momento. Habrá que buscar en la obra posterior de Morice si tuvo eco positivo esta entrevista. Habrá que buscar el saldo favorable de cuantas relaciones literarias examinemos. Instalar vasos comunicantes en el ámbito histórico y geográfico, a través de la literatura o de las ideas, a la vez que ofrece nuevas perspectivas a la crítica y a otras disciplinas puramente literarias, ayuda efectivamente a fijar simpatías y diferencias americanas. Simpatías de lo común entre nosotros y el mundo; diferencias entre el mundo y nosotros. ${ }^{35}$

ERnesto Mejía SÁNCHEZ.

Universidad Nacional Autónoma de México

33 Idem, cap. XXXIII, pp. 151-152. Alegría, obra citada, p. 262, utiliza e1 pasaje con otros fines.

34. En Arturo Marasso, Rubén Dario y su creación poética. Edición aumentada. Buenos Aires, Biblioteca Nueva, s. f., p. 41 (lámina).

35 Ya en pruebas este trabajo, encuentro entre los Fragmentos de Martí uno no identificado, pero que debe ser un borrador o proyecto de carta a Sarmiento: "Debo a V. el conocimiento de mucha palabra gráfica; la confirmación de mis prejuicios atrevidos sobre la causa inevitable de nuestras guerras en América; y el saber de su país que V. pinta en Facundo con no más fuerza que..." (Obras completas, La Habana, Editorial Nacional, 1965, vol. 22, p. 43). 